\title{
Particle phase distribution of polycyclic aromatic hydrocarbons in stormwater - Using humic acid and iron nano-sized colloids as test particles
}

Nielsen, Katrine; Kalmykova, Yuliya ; Strömvall, Ann-Margret ; Baun, Anders; Eriksson, Eva

\section{Published in:}

Science of the Total Environment

Link to article, DOI:

10.1016/j.scitotenv.2015.05.093

Publication date:

2015

Document Version

Peer reviewed version

Link back to DTU Orbit

Citation (APA):

Nielsen, K., Kalmykova, Y., Strömvall, A-M., Baun, A., \& Eriksson, E. (2015). Particle phase distribution of polycyclic aromatic hydrocarbons in stormwater - Using humic acid and iron nano-sized colloids as test particles. Science of the Total Environment, 532, 103-111. https://doi.org/10.1016/j.scitotenv.2015.05.093

\section{General rights}

Copyright and moral rights for the publications made accessible in the public portal are retained by the authors and/or other copyright owners and it is a condition of accessing publications that users recognise and abide by the legal requirements associated with these rights.

- Users may download and print one copy of any publication from the public portal for the purpose of private study or research.

- You may not further distribute the material or use it for any profit-making activity or commercial gain

- You may freely distribute the URL identifying the publication in the public portal 
1 Particle Phase Distribution of Polycyclic Aromatic Hydrocarbons in Stormwater - Using Humic Acid 2 and Iron Nano-sized Colloids as Test Particles

3

4 Katrine Nielsen $^{\mathrm{a},{ }^{*},}$, Yuliya Kalmykova ${ }^{\mathrm{b}}$, Ann-Margret Strömvall ${ }^{\mathrm{b}}$, Anders Baun ${ }^{\mathrm{a}}$, Eva Eriksson ${ }^{\mathrm{a}}$

$5 \quad *$ Corresponding author: katni@env.dtu.dk

$6 \quad{ }^{a}$ Department of Environmental Engineering, Technical University of Denmark, Miljoevej B115, DK

72800 Kgs. Lyngby, Denmark (katni@env.dtu.dk, abau@env.dtu.dk, evek@env.dtu.dk)

$8 \quad{ }^{\mathrm{b}}$ Department of Civil and Environmental Engineering, Chalmers University of Technology, 41296

9 Gothenburg, Sweden (yuliya.kalmykova@ chalmers.se, ann-margret.stromvall@ chalmers.se) 


\section{Abstract}

11 The distribution of polycyclic aromatic hydrocarbons (PAHs) in different particulate fractions in 12 stormwater: Total, Particulate, Filtrated, Colloidal and Dissolved fractions, were examined and compared to synthetic suspensions of humic acid colloids and iron nano-sized particles. The distribution of low-molecular weight (LMW PAHs), middle-molecular weight (MMW PAHs) and high-molecular weight (HMW PAHs) among the fractions was also evaluated. The results from the synthetic suspensions showed that the highest concentrations of the PAHs were found in the Filtrated fractions and, surprisingly, high loads were found in the Dissolved fractions. The PAHs identified in stormwater in the Particulate fractions and Dissolved fractions follow their hydrophobic properties. In most samples $>50 \%$ of the HMW PAHs were found in the Particulate fractions, while the LMW and MMW PAHs were found to a higher extent in the Filtrated fractions. The highest concentrations of

PAHs were present in the stormwater with the highest total suspended solids (TSS); the relative amount of the HMW PAHs was highest in the Particulate fractions (particles $>0.7 \mu \mathrm{m}$ ). The highest concentration of PAHs in the Colloidal fraction was found in the sample with occurrence of small nano-sized particles $(<10 \mathrm{~nm})$. The results show the importance of developing technologies that both can manage particulate matter but also effectively remove PAHs present in the Colloidal and Dissolved fractions in stormwater.

Keywords: Colloid enhanced transport, liquid - liquid extraction, solid phase extraction, particle sorption, urban stormwater

\section{Introduction}

During the last decades, growing urbanization and increased anthropogenic activities have turned urban stormwater into a pollution source for receiving waters (Eriksson et al., 2007; Björklund et al., 2011; Barbosa et al., 2012; Deffontis et al. 2013). The concern of pollution of receiving waters has yielded The European Water Framework Directive (2000/60/EC) for protection and restoring of clean water across Europe to ensure its long-term sustainable use. Consequently, pressures exist for implementing efforts in urban areas to collect the stormwater and remove the pollutants closer to the pollution sources, i.e. structural best management practices (BMPs) (Liu et al. 2014). The most frequently applied techniques are construction of artificial wetlands and wet stormwater ponds for sedimentation of particulate pollution (Pitcher et. al. 2004). These treatment facilities are effective if the pollutants are 
sorbed to particles which readily settles, i.e. particles > $0.45 \mu \mathrm{m}$ (Howitt et al., 2014; Bin et al., 2011; Grolimund et al., 2005; Pettersson 1998). However, from recent research, it is clear that pollutants substantially are sorbed onto colloidal particles, and therefore cannot be effectively removed in the treatment facilities operating today (Kalmykova et al. 2013, Nielsen et al. 2015). Several stormwater priority pollutants, notably toxic metals and polycyclic aromatic hydrocarbons (PAHs), have been associated with colloidal material $(<1 \mu \mathrm{m})$ in the water (Aryal et al. 2013, Xanthopoulos and Hahn 1990). Kalmykova et al. (2013) have shown that particles $<0.7 \mu \mathrm{m}$ could considerably contribute to the transport of organic pollutants in landfill leachate, stormwater from urban areas and waste-sorting sites. Despite the documented association of PAHs with colloidal particles, the related particle size 48 distributions (PSD) have not been shown. A greater knowledge of the PSD and general particle characteristics of the colloids transporting the PAHs in stormwater would benefit the targeted development of stormwater treatment facilities, and explain the reasons why PAHs are analysedin receiving waters.

Higher traffic activities have shown a positive correlation with increasing levels of PAHs in stormwater (Moilleron et al., 2002; Murakami et al., 2005; Van Metre et al., 2000). Even though emission control strategies and exchange of fuels have been implemented, increased concentrations of PAHs have been found in urban sediments (Hwang et al., 2006). An important identified source of PAHs in stormwater are highly aromatic (HA) oils added to rubber tires (Wik and Dave, 2005; Norin and Strömvall, 2004).

The categorization of PAHs according to molecular weight follows the definitions by the Agency for 58 Toxic Substances and Disease Registry (ATSDR), under the US Environmental Protection agency (U.S. EPA, 1995): Low-molecular weight PAHs (LMW PAHs) are naphthalene, acenaphthene and acenaphthylene (two and three ring structures), medium-molecular weight PAHs (MMW PAHs) are fluorene, phenanthrene, anthracene, fluoranthene and pyrene (three- and four ring structures). The group of high molecular weight PAHs (HMW PAHs) comprises PAHs with four to six rings, i.e. benzo[a]anthracene, chrysene, benzo[b]fluoranthene, benzo[k]fluoranthene, benzo[a]pyrene, dibenzo[a,h]anthracene, benzo[g,h,i]perylene and indeno[1,2,3-c,d]pyrene. Carcinogenic effects have been quantified for the MMW PAHs and HMW PAHs (Palm et al., 2011). Therefore it is important to study how the PAHs in the different groups are distributed among the Particulate, Colloidal and 
68 PAHs, combinations of different treatment technologies are needed for sustainable and efficient 69 treatment approaches for the PAHs in stormwater. This may involve a step where larger particles containing most of the HMW PAHs are separated, as for example by sedimentation, combined with techniques for sorbing or oxidizing the dissolved, LMW PAHs, as well as the colloids carrying the MMW PAHs (Kalmykova et al., 2014).

The aim of this study is to investigate the distribution of PAHs associated to nano-sized particles, 74 colloids and particulate matter in urban stormwater, collected at two different stormwater treatment facilities. The collected samples were analysed for the content of LMW PAHs, MMW PAHs and HMW PAHs in the fractions: Total-, Particulate-, Filtrated-, Colloidal- and Dissolved- fractions including nano-sized particles. As the chemical composition of the colloids and the particles, and the particle size distributions in the stormwater samples were unknown, and are expected to vary both inbetween and within runoff events, test particles based on documented humic acid nano-sized (HA-n) colloids and nano-sized iron(III) (Fe) particles in suspensions were used as references (Nielsen et al. Submitted), to investigate the distribution of PAHs among the fractions for an organic and inorganic colloid/particle suspension.

The hypotheses were that: i) The PAHs will be distributed in different fractions depending on the molecular weight and, physico-chemical properties of the PAHs, i.e. the HMW PAHs will sorb to particles, the MMW PAHs will be found the colloidal phase and the LMW PAHs in the dissolved phase (Kalmykova et al., 2013), ii) A difference in the groups of PAHs sorbed to the inorganic and organic test particles is expected, due to different sorption pattern(Boyd et al. 2001; Celis et al. 2006; Luo et al. 2008), iii) The amount of PAHs found in the Total fraction will decrease from the inlet to the outlet in the sedimentation pond and the chamber sedimentation facility due to settling, whereas the PAHs in the Filtrated fractions, i.e. Colloidal and Dissolved, it is not expected to differ substantially between the inlet and outlet, since removal of these fractions is not expected in the treatment facilities currently used (Pettersson 1999 Lead et al. 2006). 


\section{$94 \quad 2.1$ Suspensions and Samples}

\subsubsection{Preparation of Synthetic Nano-sized Particles}

A colloidal suspension with particle sizes of $160 \mathrm{~nm}$ in hydrodynamic diameter (HA-n), and a $44 \mathrm{~nm}$ in hydrodynamic diameter $(\mathrm{Fe})$ nano-sized particle suspension, derived from iron nitrate, were used as synthetic colloids and nano-sized particles to investigate the sorption of PAHs to an organic and a inorganic entity. Natural organic matter, often consisting of humic and fulvic acids, and quantified as total organic matter (TOC) (e.g. Badin et al., 2008) play an important role in the enhanced transport of pollutants in stormwater, and therefore are HA-n colloids relevant to use as test particles. It is also known that stormwater contains inorganic particles such as natural clay and silt (Grolimund et al. 2005) as well as break-debris particles derived from break wear (Peikertová et al., 2013), and iron has been analysed in high concentrations in road dust (Herngren et al. 2006). Accordingly the use of inorganic Fe nano-sized suspension as test particles is justified. The HA-n colloid and Fe particle suspensions were made following the procedure given by Florence (1982). The mixture of the Fe-n particles and HA-n colloids were found to agglomerate to particles $>200 \mathrm{~nm}$ in hydrodynamic diameter. The final HA-n colloid suspension contained $14.4 \mathrm{mg}$ Non-Volatile Organic Carbon (NVOC)/L, with a pH of 7.0 and colloids with an ionic strength of $3.5 \times 10^{-6} \mathrm{mS} / \mathrm{cm}$. The Fe particle suspension contained $47.6 \mathrm{mg}$ $\mathrm{Fe} / \mathrm{L}$ with a pH of 3.4 and an ionic strength of $0.38 \times 10^{-6} \mathrm{mS} / \mathrm{cm}$. The HA-n colloids and Fe particles are stable over a short time period ( $<2$ months) when stored at $+4{ }^{\circ} \mathrm{C}$ (Nielsen et al. 2015). For the experiments duplicate suspensions were tested, together with a mixture of the two suspensions (50\%/50\%), and a Milli-Q water solution (95\%/5\% V/V Milli-Q $\mathrm{H}_{2} \mathrm{O} /$ iso-propanol). The iso-propanol was added to the Milli-Q to better keep the PAHs in the solution, and to avoid PAH sorption to the glass surfaces.

\subsubsection{Stormwater Sampling and Sites}

Stormwater was collected by multiple grab sampling at Gårda and Järnbrott, two stormwater sedimentation facilities in the area of Gothenburg, Sweden. Samples were collected during two rain events, in the spring of 2013. At the first event only inlet stormwater was sampled ( $\mathrm{n}=1$ for each site), while at the second event both inlet and outlet stormwater were collected ( $\mathrm{n}=2$ for each site), as 
121 multiple grab samples (5 á 2 L) were pooled to yield one composite sample per event, site, and in-

122 /outlet. All sub-samples were stored at $<8^{\circ} \mathrm{C}$ in dark $2 \mathrm{~L}$ glass bottles and were extracted within $48 \mathrm{~h}$.

123 The Gårda stormwater sedimentation facility is situated in Gothenburg city (population 550,000), and

124 is connected to the E6 highway, used by 100,000 vehicles on a daily basis. The catchment is mainly 125 from the trafficked area with $\sim 0.051 \mathrm{~km}^{2}$ with $40 \%$ imperious surface. The facility manages 126 stormwater through settling and sedimentation, in seven concrete chambers in series, with a total 127 volume of $122 \mathrm{~m}^{3}$. The hydraulic retention time is 40 hours, after which the treated water is pumped via 128 a draining pipe to a nearby stream (Pettersson et al., 2005). The inlet samples were collected in 129 chamber 1 , and the outlet in chamber 7.

130 The Järnbrott stormwater facility is a stormwater pond, situated $5 \mathrm{~km}$ outside Gothenburg, with a 131 catchment of $30 \%$ commercial/industrial and $70 \%$ residential areas (Pettersson, 1999). The total area 132 is $4.78 \mathrm{~km}^{2}$, with $33 \%$ impervious surface. The area is divided with a city motorway with an annual 133 daily traffic of $\sim 40,000$ vehicles. The pond is located in a green area, with a surface area of $6200 \mathrm{~m}^{2}$, 134 and can contain $\sim 6000 \mathrm{~m}^{3}$ water, with a maximum inflow of $1100 \mathrm{l} / \mathrm{s}$, the outlet reaches a small 135 stream, which discharges into Kattegat.

\section{$136 \quad 2.2$ Phase separation}

137 To determine the concentrations of PAHs in the Total, Filtrated and Dissolved fraction (see Figure 1), 138 liquid-liquid extraction (LLE), physical filtration and solid phase extraction (SPE) was used 139 (Kalmykova et al., 2013). Particle- and Colloidal fractions were calculated, using the amounts of PAHs 140 found in the analysed fractions. 


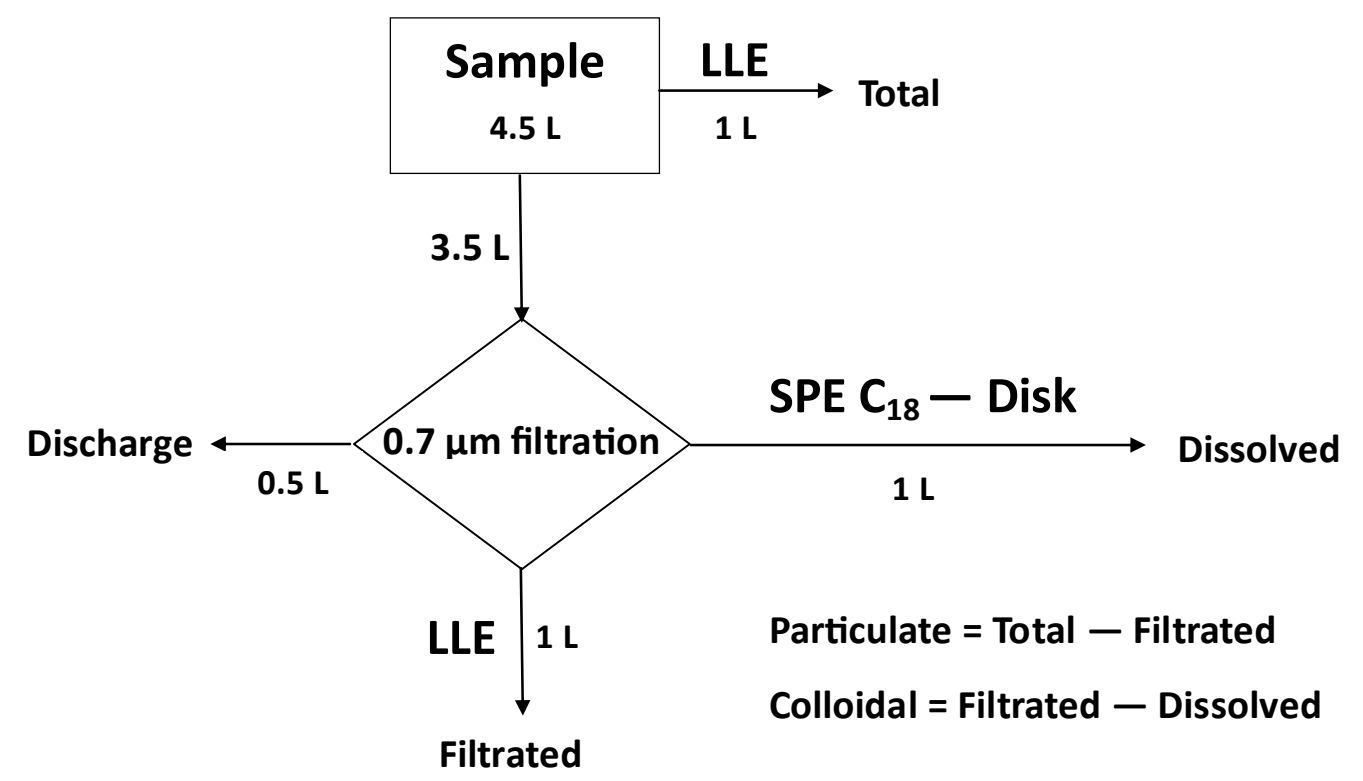

141

142 Figure 1: Flow-diagram for separating the nano-sized colloids in suspension, and thereby determine the 143 concentrations of PAHs in the fractions: Total, Filtrated and Dissolved.

144 A stock solution containing 14 selected PAHs: acenaphthene, acenaphthylene, anthracene, 145 benzo[a]anthracene, benzo[a]pyrene, benzo[b]fluoranthene, benzo[g,h,i]perylene, 146 benzo[k]fluoranthene, chrysene, fluorene, fluoranthene, naphthalene, phenanthrene and pyrene, was 147 prepared in ethanol with individual concentrations of $\sim 210 \mathrm{mg} / \mathrm{L}$. To determine the amount of PAHs in 148 the different fractions, mixtures were prepared by adding $2.5 \mathrm{~mL}$ of stock solution to a 4.5 L Milli-Q 149 water or nano-sized and colloidal particle suspension.

\section{$150 \quad 2.3$ Extraction of PAHs}

151 The mixtures were equilibrated in room temperature for 24 hours, followed by homogenization by 152 shaking before sample aliquots were taken out. The 24 hour equilibrating time was confirmed by Birch 153 et al. (2010), and the biological half-time for the chosen PAHs were in the range of 2 to 2200 days 154 (Wang et al., 2010) assuring that no biological degradation will occur during the experiments. For all 155 experiments an identical filtration and extraction procedure was used following the flow-diagram in 156 Figure 1, and were conducted in duplicates. An aliquot of $1 \mathrm{~L}$ was taken for analysis of the 157 concentration of PAHs in the Total fraction by LLE. Here $1 \mathrm{ml}$ of pyrene-d $\mathrm{d}_{10}$ in acetone $(100 \mathrm{mg} / \mathrm{L})$ 158 and $1 \mathrm{ml}$ of perylene- $\mathrm{d}_{12}$ in acetone $(100 \mathrm{mg} / \mathrm{L})$ were added as internal standards. For the Filtrated and 159 Dissolved fractions, $3.5 \mathrm{~L}$ was filtered through a $<0.7 \mu \mathrm{m}$ binder free glass fibre filter (Whatman ${ }^{\circledR}$ ). Of 
160 the filtrated sample $(3.5 \mathrm{~L}), 1 \mathrm{~L}$ was taken out for LLE and $1 \mathrm{~L}$ aliquots for SPE $\mathrm{C}_{18}$-disc; to each of 161 these, pyrene- $d_{10}$ and perylene- $d_{12}$ were added as internal standards.

162 The PAHs in the different fractions was determined using the LLE U.S. EPA Method 3510C (1996) 163 and SPE on the $\mathrm{C}_{18}$-disk (Brown et al. 2003). For LLE cyclohexane:ethyl acetate (1:1) was used as 164 solvent, and the extract was cleaned up using a Florisil column to remove polar compounds in the 165 sample (Waksmundzka-Hajnos et al. 1996). The $\mathrm{C}_{18}$-disk (Empore ${ }^{\mathrm{TM}}$ ) was conditioned, using cyclohexane:ethyl acetate $(1: 1)$ and methanol. For the $\mathrm{C}_{18}$-disk a volume of $250 \mathrm{~mL}$ could be loaded creating quadrupole loadings in order to yield the nominated $1 \mathrm{~L}$ volume. The PAHs was eluted using cyclohexane:ethyl acetate (1:1). All extracts were analysed in duplicates for the 14 specific PAHs, by GC-MS-SIM. The chromatographic separation was conducted on an Agilent 6890 gas chromatograph equipped with a, $60 \mathrm{~m} \times 0.25 \mathrm{~mm}$ i.d $\times 0.25 \mu \mathrm{m}$ film thickness, ZB-5ms column with a $5 \mathrm{~m}$ GuardZ column (Phenomenex). Splitless mode was used, and a $2 \mu \mathrm{L}$ sample was injected with the injector held at $300{ }^{\circ} \mathrm{C}$. The oven was programmed with a gradient temperature program: start $70{ }^{\circ} \mathrm{C}$, then 20 ${ }^{\circ} \mathrm{C} / \mathrm{min}$ to $300{ }^{\circ} \mathrm{C}$, then $50{ }^{\circ} \mathrm{C} / \mathrm{min}$ to $325^{\circ} \mathrm{C}$ held for $10 \mathrm{~min}$. Helium was used as carrier gas with a 1 $\mathrm{ml} / \mathrm{min}$ constant flow. Detection was achieved on an Agilent 5975C triple-axis mass-selective detector operated in SIM mode with the MS source at $230{ }^{\circ} \mathrm{C}$ and the quadrupole at $150{ }^{\circ} \mathrm{C}$.

176

177

178

179

180

181

182

183

184

185

186

187

188

\subsection{Characterization of Stormwater}

Dynamic light scattering (Zetasizer Nano ZS, Malvern) measuring in the range from $1 \mathrm{~nm}$ to $1000 \mathrm{~nm}$ was used to determine the particle size distribution (PSD) in the Filtrated and Colloidal fraction; particles in these fractions were expected to be in the nano-size range. A Coulter Counter, Multisizer ${ }^{\mathrm{TM}}$ II, measuring in the range from $2 \mu \mathrm{m}$ to $50 \mu \mathrm{m}$ was used to count the number of particles in the Total fraction. Both methods are described in Nielsen et al. (2015). The Zetasizer (Malvern) was also used for measurement of zeta potential $(\mathrm{mV})$ and ionic strength $(\mathrm{mS} / \mathrm{cm})$.

Total suspended solids were measured using the same glass fibre filter $(0.7 \mu \mathrm{m})$ as in the fractionation following the U.S. EPA Method no. 160.2. Element analysis were made on unfiltered samples: aluminium ( $\mathrm{Al})$, antimony $(\mathrm{Sb})$, arsenic (As), barium (Ba), cadmium calcium $(\mathrm{Ca})$, cadmium $(\mathrm{Cd})$, cobalt $(\mathrm{Co})$, chromium $(\mathrm{Cr})$, copper $(\mathrm{Cu})$, iron $(\mathrm{Fe})$, potassium $(\mathrm{K})$, lithium $(\mathrm{Li})$, magnesium $(\mathrm{Mg})$ molybdenum (Mo), manganese $(\mathrm{Mn})$, nickel $(\mathrm{Ni})$, phosphorus $(\mathrm{P})$, lead $(\mathrm{Pb})$, sodium $(\mathrm{Na})$, selenium (Se), silicon ( $\mathrm{Si}$ ), strontium (Sr), sulphur (S), titanium (Ti), vanadium (V) and zinc $(\mathrm{Zn})$, and were 
189 analysedusing ICP-OES: Varian, Vista MPX, after acid digestion according to the Standard DS/EN

190 13656; NVOC was measured by Shimadzu, TOC-V wp.

\section{$191 \quad$ 2.5. Data analysis and statistical tests}

192 The concentrations of the PAHs were derived from the calibration curve and calculated as averages of

193 duplicates. The $\mu$ mol loads were corrected according to the internal standard (pyrene-d ${ }_{10}$ ). To calculate 194 the percentage distribution (DIS\%), the amount in $\mu$ mol of the PAHs in each of the fractions 195 Particulate, Filtrated, Colloidal and Dissolved (see Figure 1), have been divided with the amount 196 ( $\mu \mathrm{mol}$ ) of PAHs in the Total fraction. The recovery of the Total fraction was calculated by dividing the 197 spiked amount of PAHs, with the quantified amount of PAHs in the Total fraction. For each fraction 198 the relative percentage (REL\%) was calculated for the low-, medium- and high-weighted PAHs based 199 on the total sum of $(\mu \mathrm{mol})$ PAH. When nothing else is noted, the statistical comparison of 200 measurements was conducted using Students $t$-test, where $p<0.05$ indicates no statistically significant 201 difference between measurements. The statistical calculations were performed using the Graph Pad 202 Prism Software.

\section{$203 \quad 3$ Results}

\section{3.1 PAHs extractions from synthetic nano-sized colloids and particles in suspension}

205 The distribution of PAHs among the fractions, i.e. DIS\% among Total, Particulate, Filtrated, Colloidal 206 and Dissolved, in the three synthetic suspensions containing colloids and nano-sized particles are 207 presented in Table 1, together with the relative composition of the PAHs presented as REL\% in Figure 208 2. In the Milli-Q water spiked with PAHs without added nano-sized particles, 63\% of the PAHs in the 209 Total fraction were found in the Particulate fraction. This is explained by sorption of PAHs on the 210 surfaces in the glass-fibre filter. Sorption of PAHs on glass surfaces is a well-known and inevitable 211 problem (Qian et al. 2011); the sorption was shown to decrease with increasing ration of solution 212 volume to contacted surface area (V/S), by using silanized glass and co-solvents. Humic acids were 213 shown to act as co-solvent and increased the solubilisation of volatile organic compounds (Sato et al. 214 2005). This may explain the lower distribution of $40 \%$ PAHs in the Particulate fraction in the 215 suspension containing HA-n colloids. . The loss in the filters were much lower when the colloids were 216 added; therefore it was assumed that the loss due to sorption on the glass-fibre filter will be even lower 217 during filtration of the real stormwater samples, because the glass surfaces are quickly covered by 
218 particles. Losses due to glass surface sorption is not possible to quantify; thus the figures in this study 219 are not corrected for the sorption effect. The low recovery from the Original added (39 $\mu \mathrm{mol})$ in the 220 Total fractions of $28-49 \%$, are also explained by sorption on the glass equipment.

221 The distribution of the PAHs among the fractions showed that the highest amounts of PAHs were 222 present in the Filtrated fractions in all the synthetic suspensions. This indicates that the PAHs were 223 dissolved or sorbed onto the HA-n colloids and Fe-n particles and, thus, passed through the $0.7 \mu \mathrm{m}$ 224 filter. Notable, high amounts of the PAHs were found in the Dissolved fraction. For the sample 225 containing Fe particles, as much as $75 \%$ of the Total fraction was distributed to the Dissolved fraction. 226 It is possible that the Colloidal phase is underestimated and a part of it measured as Dissolved, as both 227 the HA and Fe particles may be sorbed in the $\mathrm{C}_{18}$-material in the SPE disk. 
Table 1. Distribution of PAHs among fractions in the suspensions with different synthetic nano-sized colloids.

\begin{tabular}{|c|c|c|c|c|c|c|c|c|c|}
\hline & \multicolumn{3}{|c|}{ Milli-Q water } & \multicolumn{2}{|c|}{ Fe-n particles } & \multicolumn{2}{|c|}{ HA-n colloids } & \multicolumn{2}{|c|}{$\begin{array}{l}\text { Fe-n particles + HA- } \\
\text { n colloids }\end{array}$} \\
\hline & PAHs & $\mu \mathrm{mol}$ & DIS\% $^{a}$ & $\mu \mathrm{mol}$ & DIS\% $^{a}$ & $\mu \mathrm{mol}$ & DIS\% $^{a}$ & $\mu \mathrm{mol}$ & DIS\% $^{a}$ \\
\hline \multirow{4}{*}{ Orginal added } & LMW & 11 & & 11 & & 11 & & 11 & \\
\hline & MMW & 16 & & 16 & & 16 & & 16 & \\
\hline & HMW & 23 & & 23 & & 23 & & 23 & \\
\hline & $\Sigma \mathrm{PAHs}$ & 39 & & 39 & & 39 & & 39 & \\
\hline \multirow{4}{*}{ Total fraction ${ }^{c}$} & LMW & 3.4 & & 2.2 & & 2.6 & & 3.3 & \\
\hline & MMW & 5.9 & & 3.7 & & 5.1 & & 6.1 & \\
\hline & HMW & 9.7 & & 5.2 & & 6.1 & & 6.6 & \\
\hline & $\sum \mathrm{PAHs}$ & 19 & $100\left(49^{d}\right)$ & 11 & $100\left(28^{d}\right)$ & 14 & $100\left(36^{d}\right)$ & 15 & $100\left(38^{d}\right.$ \\
\hline \multirow{4}{*}{$\begin{array}{l}\text { Particulate fraction } \\
>0.7 \mu \mathrm{m}^{\mathrm{d}}\end{array}$} & LMW & 1.5 & 44 & 0.36 & 16 & 0.8 & 31 & 1.1 & 33 \\
\hline & MMW & 2.6 & 44 & 0.66 & 18 & 1.9 & 37 & 2.8 & 46 \\
\hline & HMW & 7.4 & 76 & 2.6 & 50 & 2.9 & 48 & 3.7 & 56 \\
\hline & $\Sigma \mathrm{PAHs}$ & 12 & 63 & 3.7 & 34 & 5.6 & 40 & 7.6 & 51 \\
\hline \multirow{4}{*}{$\begin{array}{l}\text { Filtrated fraction }< \\
0.7 \mu \mathrm{m}^{\mathrm{e}}\end{array}$} & LMW & 1.9 & 56 & 1.9 & 86 & 1.8 & 69 & 2.1 & 64 \\
\hline & MMW & 3.3 & 56 & 3.1 & 84 & 3.2 & 63 & 3.3 & 54 \\
\hline & HMW & 2.3 & 24 & 2.6 & 50 & 3.2 & 52 & 2.9 & 44 \\
\hline & $\Sigma \mathrm{PAHs}$ & 7.5 & 39 & 7.5 & 68 & 8.3 & 59 & 8.4 & 56 \\
\hline \multirow{4}{*}{ Colloidal fraction ${ }^{f}$} & LMW & - & & 0.27 & 12 & 0.22 & 8 & 0.18 & 5 \\
\hline & MMW & - & & 0.27 & 7 & 0.43 & 8 & 0.46 & 8 \\
\hline & HMW & - & & - & - & - & - & 2.1 & 32 \\
\hline & $\Sigma \mathrm{PAHs}$ & - & & 0.54 & 5 & $0-65$ & 5 & 2.8 & 19 \\
\hline \multirow{4}{*}{ Dissolved fraction ${ }^{g}$} & LMW & 2.2 & 65 & 1.6 & 73 & 1.6 & 62 & 1.9 & 58 \\
\hline & MMW & 4.4 & 75 & 2.8 & 76 & 2.8 & 55 & 2.9 & 48 \\
\hline & HMW & 2.6 & 27 & 3.9 & 75 & 3.3 & 54 & 0.79 & 12 \\
\hline & $\Sigma \mathrm{PAHs}$ & 9.3 & 49 & 8.2 & 75 & 7.7 & 55 & 5.6 & 37 \\
\hline
\end{tabular}

${ }^{\mathrm{a}} \mathrm{DIS} \%=$ distribution\% calculated from the quantified $\sum$ PAHs ( $\mu$ mol) as well as by LMW PAHs, $-\mathrm{M}$ and $-\mathrm{H}$ in each Particulate, Filtrated,

Colloidal and Dissolved fractions divided with the quantified corresponding mass ( $\mu$ mol) in the Total fraction ${ }^{\mathrm{c}}$ Total=chemical quantified

PAHs in the original sample; ${ }^{\mathrm{d}}$ The Recovery $\%=$ calculated by dividing the $\sum$ PAHs quantified in Total in $\mu$ mol with the $\sum$ PAHs in $\mu$ mol added to the original samples; ${ }^{\mathrm{e}}$ Particulate $=$ calculated as the PAH quantified in Total $-\mathrm{PAHs}$ quantified in Filtrated; ${ }^{\mathrm{f}}$ Filtrated $=$ PAHs quantified in samples after filtration through $0.7 \mu \mathrm{m}$ glass fibre; ${ }^{\mathrm{g}}$ Colloidal $=$ calculated as Filtrated PAHs - Dissolved; ${ }^{\mathrm{i}}$ Dissolved $=$ PAHs

235 quantified on disk SPE. 
Particulate $>0.7 \mu \mathrm{m}$

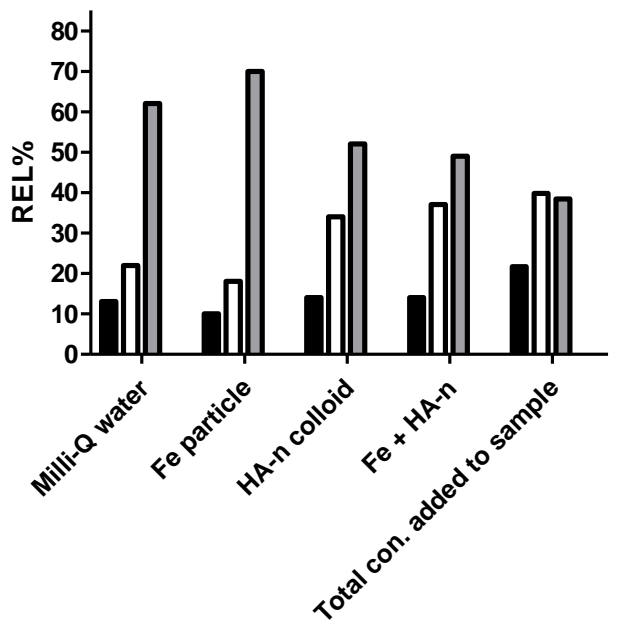

Colloidal after disk

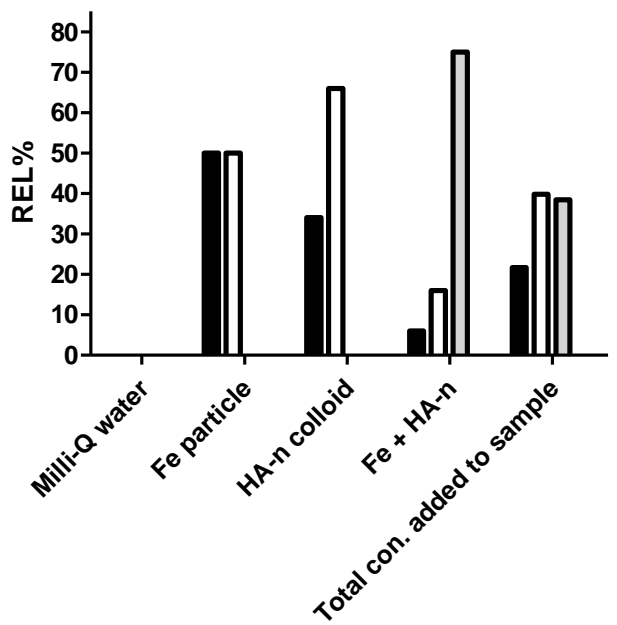

Filtrated $<0.7 \mu \mathrm{m}$
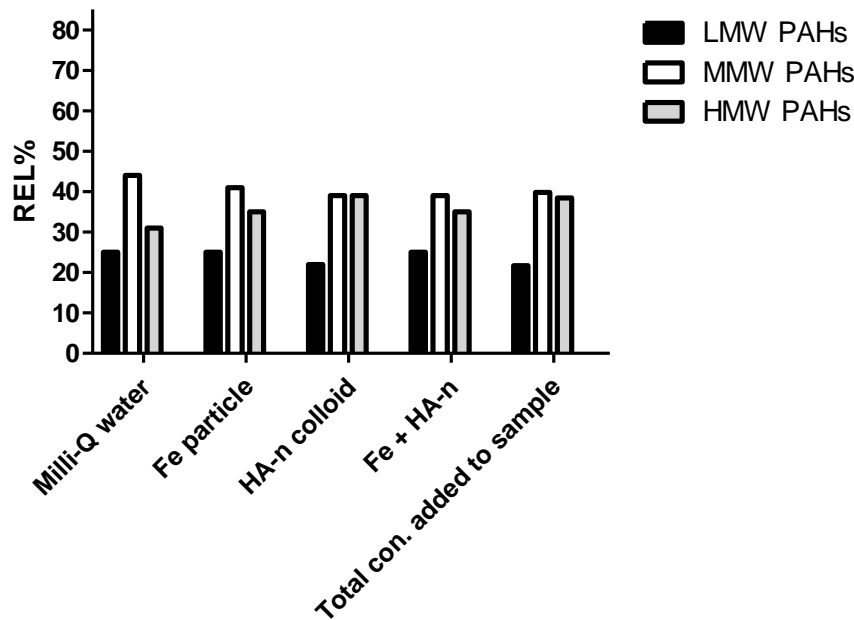

Dissolved after disk

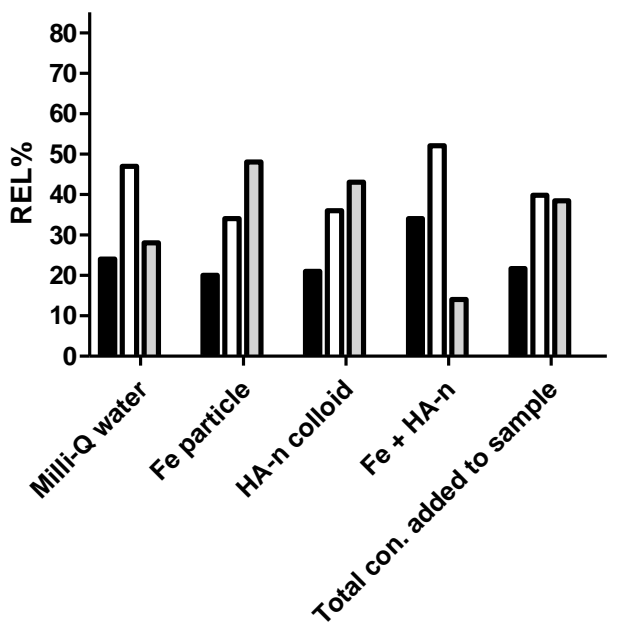

238 Figure 2: Relative composition (DIS\%) ${ }^{\text {a }}$ of LMW, MMW and HMW PAHs, in the Milli-Q solution and the three suspensions with Fe particles, HA-n colloids and the mixture of Fe particles and HA-n colloids. ${ }^{\mathrm{a}} \mathrm{REL} \%$ calculated by the quantified $\mu$ mol of the LMW PAHs, $-\mathrm{M}$ and $-\mathrm{H}$ divided with the quantified $\sum \mathrm{PAHs}$ in each sample

242 The relative composition of the LMW, MMW and HMW PAHs were approximately the same in the

243 Filtrated and the Dissolved phases (except for the much lower HMW PAHs for the Dissolved in the 244 Fe+HA suspension). Instead, the HMW PAHs in the Filtrated Fe+HA suspension were found in the 245 Colloidal fraction. The concentrations of PAHs found in the Particulate fractions vs. the Dissolved 246 fractions followed their hydrophobic properties; of the HMW PAHs $50-75 \%$ was found in the 247 Particulate fractions, while the LMW PAHs and MMH were found to a higher extent, $50-75 \%$, in 
248 the Dissolved fractions (see DIS\% in Table 1). This is explained by the partitioning and the higher $249 \log \mathrm{K}_{\text {ow }}$ of the HMW PAHs and thus a higher ability to sorb to surfaces compared to the LMW 250 PAHs.

\section{$251 \quad 3.2$ Physico-chemical parameters in stormwater}

252 The stormwater samples were analysed for physical parameters, PSD and concentration of selected 253 metals, see Table 2. The quantifications of TSS from Järnbrott showed lower concentrations 254 compared to Gårda. At Gårda the two inlet samples were quantified to $150 \mathrm{mg} / \mathrm{L}$ and $180 \mathrm{mg} / \mathrm{L}$ 255 TSS, and an unexpected high TSS at the outlet of $400 \mathrm{mg} / \mathrm{L}$ (Pettersson et al. 2005). Even though 256 the TSS increased from the inlet to the outlet, did the PDS, neither the hydrodynamic diameter nor 257 the Coulter counter diameter, show any statistically difference of the sizes of the particles (Table 2). 258 The measurements of $\mathrm{pH}$ did not show any statistical difference between samples from inlet and 259 outlet, nor between locations ( $p<0.05)$ except for one of the inlet samples from Gårda showing 260 more of an unbuffered rainwater of $\mathrm{pH}$ 4.6. The turbidity measured in the inlet sample for Event 2 261 at Gårda, were found to be significantly different from the rest of the measurements. This could be 262 explained by high turbulence in the underground sedimentation tanks. When the outlet samples 263 were collected, all tanks were filled with water indicating a blockage in the outgoing water. The 264 high water level and heavy rain in the days before sampling could have created turbulence in the 265 tanks, re-suspending some of sediment and thereby given the higher turbidity for the samples.

266 Table 2: Physico-chemical parameters, particle size distribution and major and minor element 267 concentrations measured in the stormwater.

\section{Gårda Järnbrott}

\begin{tabular}{|c|c|c|c|c|c|c|}
\hline & \multicolumn{2}{|c|}{ Event 1} & Event 2 & \multicolumn{2}{|c|}{ Event 1} & \multirow{2}{*}{$\begin{array}{l}\text { Event } 2 \\
\text { Outlet }\end{array}$} \\
\hline & Inlet & Inlet & Outlet & Inlet & Inlet & \\
\hline $\mathrm{pH}$ & 6.7 & 4.6 & 6.6 & 7.6 & 6.9 & 7.6 \\
\hline $\mathrm{EC}(\mu \mathrm{S} / \mathrm{cm})$ & 27000 & 370 & 290 & 750 & 370 & 440 \\
\hline lonic strength $\times 10^{-6}(\mathrm{mS} / \mathrm{cm})$ & 50 & 5.2 & 6.4 & 1.3 & 7.6 & 6.8 \\
\hline TSS (mg/L) & $150 \pm 20$ & $180 \pm 3.5$ & $400 \pm 7.3$ & $75 \pm 1.4$ & $24 \pm 6.5$ & $20 \pm 0.9$ \\
\hline Turbidity (NTU) & 90 & 220 & 310 & 90 & 20 & 27 \\
\hline Zeta potential $(\mathrm{mV})$ & -18 & -22 & -21 & -24 & -22 & -26 \\
\hline $\begin{array}{l}\text { Hydrodynamic diameter in } \mathrm{nm} \\
\text { range }^{\text {a }}\end{array}$ & $39-150$ & $29-95$ & $7.8-170$ & $5.8-230$ & $10-230$ & $16-230$ \\
\hline $\begin{array}{l}\text { Hydrodynamic diameter in } \mu \mathrm{m} \\
\text { range }^{b}\end{array}$ & 7.2 & 4.9 & 6.5 & 11 & 6.2 & 6.0 \\
\hline NVOC (mg/L) & 300 & 290 & 270 & 250 & 290 & 270 \\
\hline $\begin{array}{l}\text { Concentration of elements } \\
(\mathrm{mg} / \mathrm{L})\end{array}$ & & & & & & \\
\hline
\end{tabular}




\begin{tabular}{|c|c|c|c|c|c|c|}
\hline Al & 1.9 & 5.4 & 2.4 & 1.5 & 0.47 & 0.42 \\
\hline $\mathrm{Ca}$ & 59 & 9.1 & 15 & 32 & 23 & 18 \\
\hline $\mathrm{Fe}$ & 5.2 & 13 & 5.8 & 5.3 & 1.1 & 1.1 \\
\hline $\mathrm{K}$ & 30 & 5.8 & 5.3 & 6.6 & 46 & 3.5 \\
\hline Mg & 28 & 5.4 & 4.2 & 6.3 & 3.5 & 3.0 \\
\hline $\mathrm{Na}$ & 350 & 36 & 39 & 81 & 42 & 3.7 \\
\hline \multicolumn{7}{|l|}{$\begin{array}{l}\text { Concentration of elements } \\
(\mu \mathrm{g} / \mathrm{L})\end{array}$} \\
\hline As & BDL & BDL & BDL & BDL & $\mathrm{BDL}$ & $\mathrm{BDL}$ \\
\hline $\mathrm{Ba}$ & 110 & 87 & 54 & 55 & 26 & 21 \\
\hline $\mathrm{Cd}$ & BDL & BDL & $\mathrm{BDL}$ & $\mathrm{BDL}$ & $\mathrm{BDL}$ & BDL \\
\hline Co & 8.8 & 13 & 6.0 & 2.2 & $\mathrm{BDL}$ & $\mathrm{BDL}$ \\
\hline $\mathrm{Cr}$ & 9.4 & 25 & 16 & 4.8 & 1.4 & $\mathrm{BDL}$ \\
\hline $\mathrm{Cu}$ & 110 & 140 & 64 & 53 & 15 & 17 \\
\hline Li & 11 & 9.6 & 6.0 & 5.7 & 3.3 & 2.9 \\
\hline Mn & 270 & 220 & 110 & 190 & 58 & 55 \\
\hline Mo & 13 & 3.6 & 2.9 & 1.9 & 1.3 & BDL \\
\hline $\mathbf{N i}$ & 9.6 & 12 & 6.2 & 6.1 & 2.8 & 2.4 \\
\hline $\mathbf{P}$ & 220 & 350 & 280 & 570 & 84 & 87 \\
\hline $\mathrm{Pb}$ & 5.8 & 16 & 7.8 & 6.3 & 2.6 & 2.2 \\
\hline$s$ & 21000 & 1700 & 3200 & 9600 & 7000 & 5000 \\
\hline $\mathrm{Sb}$ & 7.9 & 11 & 6.5 & 2.7 & $\mathrm{BDL}$ & $\mathrm{BDL}$ \\
\hline $\mathrm{Se}$ & 4.0 & BDL & BDL & $\mathrm{BDL}$ & $\mathrm{BDL}$ & $\mathrm{BDL}$ \\
\hline Si & 8500 & 11000 & 8000 & 6900 & 6400 & 6000 \\
\hline Sn & 17 & 23 & 15 & 13 & 11 & 8.9 \\
\hline $\mathrm{Sr}$ & 280 & 50 & 59 & 100 & 71 & 57 \\
\hline $\mathrm{Ti}$ & $\mathrm{BDL}$ & $\mathrm{BDL}$ & $\mathrm{BDL}$ & $\mathrm{BDL}$ & $\mathrm{BDL}$ & $\mathrm{BDL}$ \\
\hline V & 10 & 19 & 8.7 & 6.7 & 1.5 & 1.8 \\
\hline $\mathrm{Zn}$ & 350 & 460 & 270 & 220 & 50 & 62 \\
\hline
\end{tabular}

$B D L=$ Below Detection Limit $(1.3 \mu \mathrm{g} / \mathrm{L}),{ }^{a}$ size at $95 \%$ accumulated volume (Nielsen et al.

269 2015)measured with Coulter counter, ${ }^{b}$ range given for where nano-particles were observed, when

270 using volume distribution, the samples have been filtrated through a $0.45 \mu \mathrm{m}$ filter before filtration

271 measured with Zetasizer

272 The particle size distribution, measured with the Coulter counter showed that the majority of the 273 particles were smaller than $10 \mu \mathrm{m}$ in diameter, though the accumulated mean diameters were $8-12$ 
$\mu \mathrm{m}$. The Zetasizer measurement showed evidence of nano-particles in all of the samples, but an exact size distribution is not possible to give due to the heterogeneity of the samples (Nielsen et al. submitted). As illustrated in Figure 3, the particle size distributions showed hydrodynamic diameters around $100 \mathrm{~nm}$ but the suspensions were highly poly-dispersed hampering accurate interpretations of the distribution curves.

The zeta potential were for all samples found to be negative, though the magnitude of -25 to -17 $\mathrm{mV}$ indicates instability (Cho et al. 2012), i.e. prone to coagulate and flocculate. A negative surface charge of the particles, is consistent with particles containing organic acids e.g. fulvic and humic acid and have been documented in literature (Kayhanian et al. 2012, Nielsen et al. 2015).

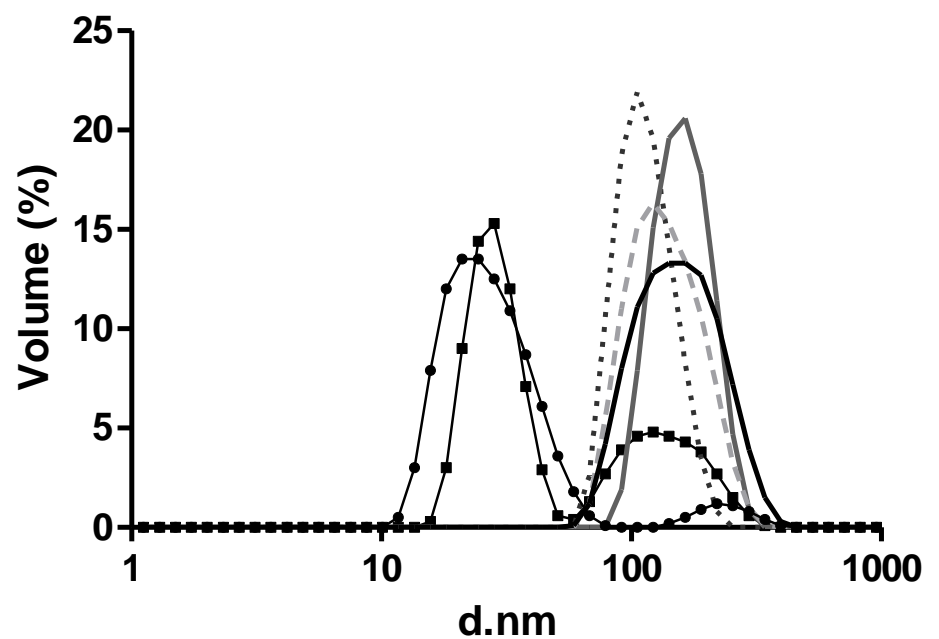

- Gårda in event 1

.... Gårda In event 2

$\rightarrow$ Gårda Out event 2

$\rightarrow$ Järnbrott in event 1

— Järnbrott In event 2

- - - Järnbrott Out event 2

284 Figure 3: Particle size distribution (PSD) of nano-particles in stormwater measured with a Zetasizer 285 on filtrated samples.

\subsection{Polycyclic aromatic hydrocarbons in stormwater}

287 The stormwater samples, presented in Table 3 for Gårda, and Table 4 for Järnbrott, all contained 288 PAHs in concentrations from 3.2 to $139 \mu \mathrm{g} / \mathrm{L}$. These concentrations were higher than previously 289 reported by Pettersson et al. (2005), where the PAHs-16 at Gårda was ranging in the inlet between $2902.6-6.9 \mu \mathrm{g} / \mathrm{L}$, and outlet, between $0.56-1.6 \mu \mathrm{g} / \mathrm{L}$. Comparatively, PAHs measured in urban snow 291 at Gårda was as high as $15 \mu \mathrm{g} / \mathrm{L}$ (Björklund et al., 2011). The high concentrations measured in this 292 study are explained by the relatively long periods of dry weather before sampling, i.e. 8 days before 293 Event 1, and 6 days of dryness before Event 2. During the dry periods, deposition of the pollutants 294 is accumulated on the surfaces and cause high concentrations of pollutants in the stormwater of the 295 coming rain event. Another explanation is that the samples in this study were grab sampled, and the 
water sample in the earlier study were taken by flow proportional samplers and yielded event mean concentrations. The PAH concentrations in this study are within the range $(<0.01-180 \mu \mathrm{g} / \mathrm{L})$ previously found in stormwater and road runoff, though they notably are in the higher range (Makepeace et al., 1995; Eriksson, 2002; Göbel et al., 2007; Birch et al., 2011). Both parking lot and roof runoff have, however, been quantified with substantially higher PAH concentrations, mainly related to site-specific pollution sources (Eriksson, 2002).

The distribution of PAHs among the fractions in the stormwater (Tables 3 and 4, and Figure 4) showed that high loads of PAHs were found in several of the Particulate fractions at both locations, but the variability was substantial, especially at Event 2 where the Gårda inlet had $32 \%$ of the PAHs in the Particulate phase, compared to the outlet where as much as $98 \%$ of the PAHs were found on the particles. This is explained by re-suspension of settled sediments caused by the turbulence in the facility during the heavy rain fall, and the thereby much higher value of TSS (Table 2) found in the

308 Gårda outlet samples.

Gårda

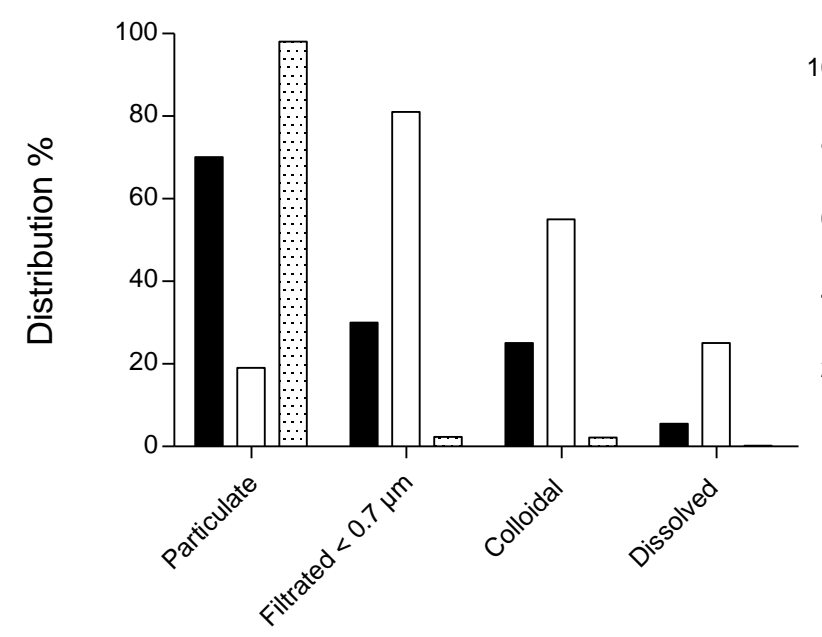

Järnbrott

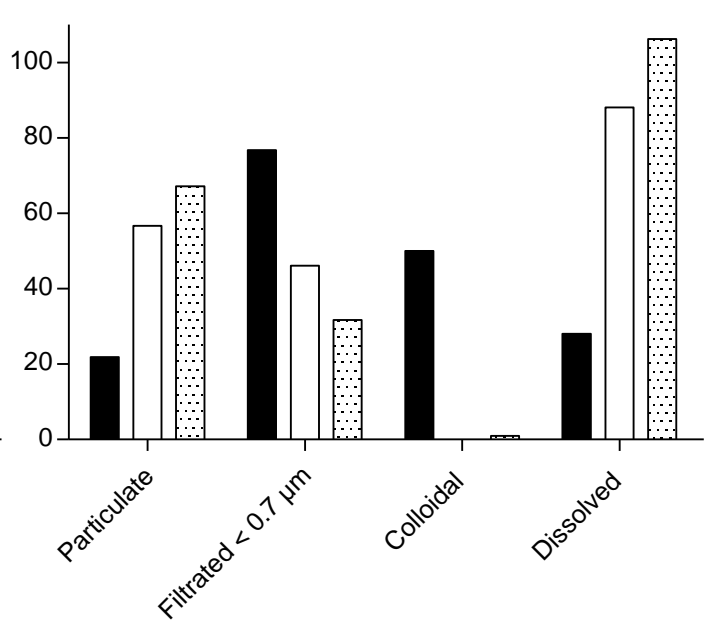

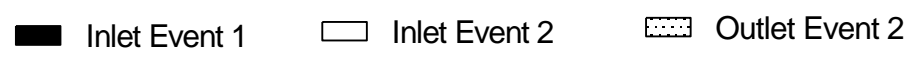

310 Figure 4: Distribution of PAHs among the different fractions at the two locations.

311 The PAHs in the Filtrated fractions were lower, but also had a large variability, e.g. from the Event 3122 outlet Gårda of only $2.4 \%$ PAHs in the Filtrated till the $81 \%$ in the inlet sample.. In the Filtrated 313 fractions it was a large difference in the composition of fractions between Gårda and Järnbrott, 314 where samples at Gårda had most of the PAHs in the Colloidal fractions, meanwhile at Järnbrott 315 high concentrations were measured in the Dissolved fraction during event 2. The Gårda samples 316 (event 2, out) had the highest concentration of PAHs in the particulate fraction, and the high 
317 concentrations are explained by the high TSS value in this sample. The Järnbrott sample (event 1, 318 in) with a much lower TSS showed very high amount in the Filtrated and Colloidal fraction; here 319 the occurrence of small particles $(<100 \mathrm{~nm})$ may explain the high concentrations in the colloidal 320 fraction.

321 The relative composition (Table 3 and 4) show a low proportion of LMW PAHs in the stormwater 322 samples, and especially at the Event 1, which had a long pre-existing dry period ( $\sim 8$ days) before 323 the sampling which caused a possible volatilization of the LMW PAHs from the urban surfaces. 324 The samples with the highest loads of the LMW PAHs were the inlet samples at the Event 2 with 325 heavy rain shortly before the sampling; this is as could be expected since the LMW PAHs are the 326 most water soluble and volatile of the 14 PAHs. At both sites the MMW PAHs was dominating, and 327 as earlier reported with a possible sources from both rubber tires and diesel exhausts (Strömvall et 328 al., 2006). The highest amounts of the HMW PAHs were found in the outlet samples for Event 2. 329 Otherwise, the relative loads of the HMW PAHs in the Particulate fractions were highest in the 330 samples with high TSS and the smallest particles (Figure 2), i.e. Gårda out Event 2 and Järnbrott in 331 Event 1. This is explained by the higher $\log \mathrm{K}_{\mathrm{ow}}$ of the HMW PAHs and their higher ability to sorb 332 to particle surfaces and the high active surfaces of the smallest particles. 
Table 3. Distribution of PAHs among fractions, and the relative composition, in samples from the Gårda sedimentation chamber facility.

\begin{tabular}{|c|c|c|c|c|c|c|c|c|c|c|}
\hline & & $\mu g / L$ & $\begin{array}{l}\text { In Event } 1 \\
\text { DIS\% }^{\mathrm{a}}\end{array}$ & REL\% ${ }^{b}$ & $\mu \mathrm{g} / \mathrm{L}$ & $\begin{array}{l}\text { In Event } 2 \\
\text { DIS\% }^{\mathrm{a}}\end{array}$ & REL\% ${ }^{\mathrm{b}}$ & $\mu \mathrm{g} / \mathrm{L}$ & $\begin{array}{l}\text { Out Event } \\
2 \\
\text { DIS\% }^{\mathrm{a}}\end{array}$ & REL\% ${ }^{\mathrm{b}}$ \\
\hline \multirow{4}{*}{ Total fraction ${ }^{c}$} & LMW & 0.062 & & \multirow{2}{*}{0.15} & 8.9 & & 18 & 11 & & \\
\hline & MMW & 38 & & & 23 & & 45 & 64 & & 8 \\
\hline & HMW & 2.4 & & $\begin{array}{l}94 \\
58\end{array}$ & 19 & & 37 & 63 & & 46 \\
\hline & $\sum \mathrm{PAHs}$ & 40 & 100 & & 50 & 100 & & 139 & 100 & \\
\hline \multirow{4}{*}{$\begin{array}{l}\text { Particulate fraction } \\
>0.7 \mu \mathrm{m}^{\mathrm{d}}\end{array}$} & LMW & 0.030 & & \multirow{4}{*}{$\begin{array}{l}0.11 \\
92 \\
8.1\end{array}$} & $<$ d.I. ${ }^{h}$ & & \multirow{4}{*}{$\begin{array}{l}<\text { d.I. }{ }^{\text {h }} \\
88 \\
12\end{array}$} & 11 & & \multirow{4}{*}{$\begin{array}{l}8.3 \\
45 \\
47\end{array}$} \\
\hline & MMW & 26 & & & 14 & & & 61 & & \\
\hline & HMW & 2.3 & & & 1.9 & & & 63 & & \\
\hline & $\sum \mathrm{PAHs}$ & 28 & 70 & & 9.7 & 32 & & 135 & 98 & \\
\hline \multirow{4}{*}{$\begin{array}{l}\text { Filtrated fraction }< \\
0.7 \mu \mathrm{m}^{\mathrm{e}}\end{array}$} & LMW & 0.031 & & \multirow{4}{*}{$\begin{array}{l}0.26 \\
99 \\
0.61\end{array}$} & 15 & & 37 & 0.031 & & \multirow{4}{*}{$\begin{array}{l}0.94 \\
98 \\
1.1\end{array}$} \\
\hline & MMW & 12 & & & 8.9 & & 22 & 3.2 & & \\
\hline & HMW & 0.074 & & & 17 & & 41 & 0.037 & & \\
\hline & $\sum \mathrm{PAHs}$ & 12 & 30 & & 41 & 81 & & 3.3 & 2.4 & \\
\hline \multirow{4}{*}{ Colloidal fraction ${ }^{\dagger}$} & LMW & $<$ d.I. ${ }^{n}$ & & \multirow{4}{*}{$\begin{array}{l}<\text { d.I. }{ }^{h} \\
100 \\
<\text { d.I. }{ }^{h}\end{array}$} & 14 & & \multirow{4}{*}{$\begin{array}{l}50 \\
31 \\
20\end{array}$} & $<\mathrm{d} . \mathrm{I}^{\mathrm{h}}$ & & $<$ d.I. ${ }^{n}$ \\
\hline & MMW & 11 & & & 8.6 & & & 3.0 & & 100 \\
\hline & HMW & $<$ d.I. ${ }^{\text {h }}$ & & & 5.4 & & & $<$ d...$^{h}$ & & $<$ d...$^{h}$ \\
\hline & $\sum \mathrm{PAHs}$ & 10 & 27 & & 28 & 56 & & 3.0 & 2.2 & \\
\hline \multirow{4}{*}{ Dissolved fraction ${ }^{g}$} & LMW & 0.062 & & 2.8 & 1.2 & & \multirow{4}{*}{$\begin{array}{l}9.6 \\
2.4 \\
88\end{array}$} & 0.031 & & \multirow{4}{*}{$\begin{array}{l}10 \\
77 \\
12\end{array}$} \\
\hline & MMW & 0.99 & & \multirow{3}{*}{$\begin{array}{l}44 \\
53\end{array}$} & 0.30 & & & 0.23 & & \\
\hline & HMW & 1.2 & & & 11 & & & 0.037 & & \\
\hline & $\sum$ PAHs & 2.2 & 5.6 & & 13 & 25 & & 0.30 & 0.22 & \\
\hline
\end{tabular}

${ }^{\mathrm{a}} \mathrm{DIS} \%=$ distribution\% calculated from the quantified $\sum$ PAHs $(\mu \mathrm{mol})$ in each Particulate, Filtrated, Colloidal and Dissolved fractions divided with the $\sum$ PAHs $(\mu \mathrm{mol})$ quantified in the Total fraction; ${ }^{b} \mathrm{REL} \%=$ relative $\%$ calculated by the $\mu \mathrm{mol}$ of the LMW PAHs, $-\mathrm{M}$ and $-\mathrm{H}$ divided with the $\sum$ PAHs in each sample; ${ }^{\mathrm{C}}$ Total $=$ quantified $\sum$ PAHs in the original sample; ${ }^{\mathrm{d}}$ Particulate $=$ calculated as PAHs quantified in Total - PAHs quantified in Filtrated; ${ }^{\mathrm{e}}$ Filtrated= PAHs quantified in samples after filtrations through $0.7 \mu \mathrm{m}$ glass fibre filter; ${ }^{\mathrm{f}}$ Colloidal $=$ calculated as Filtrated PAHs - Dissolved; ${ }^{\mathrm{g}}$ Dissolved = PAHs analysed on disk SPE. 
342 Table 4. Distribution of PAHs among fractions, and the relative composition, in samples from the Järnbrott sedimentation pond.

\begin{tabular}{|c|c|c|c|c|c|c|c|c|c|c|}
\hline & & $\mu \mathrm{g} / \mathrm{L}$ & $\begin{array}{l}\text { In Event } 1 \\
\text { DIS\% }^{\mathrm{a}}\end{array}$ & REL\% ${ }^{\mathrm{b}}$ & $\mu \mathrm{g} / \mathrm{L}$ & $\begin{array}{l}\text { In Event } 2 \\
\text { DIS\%a }\end{array}$ & REL\% ${ }^{\mathrm{b}}$ & $\mu \mathrm{g} / \mathrm{L}$ & $\begin{array}{l}\text { Out Event } \\
2 \\
\text { DIS\% }^{a}\end{array}$ & REL\% ${ }^{b}$ \\
\hline Total fraction $^{c}$ & $\begin{array}{l}\text { LMW } \\
\text { MMW } \\
\text { HMW } \\
\text { ¿PAHs }\end{array}$ & $\begin{array}{l}0.06 \\
57 \\
15 \\
71\end{array}$ & $\begin{array}{l}0.08 \\
79 \\
21 \\
100\end{array}$ & & $\begin{array}{l}12 \\
19 \\
20 \\
52\end{array}$ & $\begin{array}{l}17 \\
26 \\
28 \\
\\
100\end{array}$ & & $\begin{array}{l}0.031 \\
1.9 \\
1.3 \\
3.2\end{array}$ & $\begin{array}{l}0.96 \\
59 \\
40 \\
100\end{array}$ & \\
\hline $\begin{array}{l}\text { Particulate fraction > } \\
0.7 \mu \mathrm{m}^{\mathrm{d}}\end{array}$ & $\begin{array}{l}\text { LMW } \\
\text { MMW } \\
\text { HMW } \\
\text { ¿PAHs }\end{array}$ & $\begin{array}{l}0.031 \\
3.7 \\
12 \\
16\end{array}$ & 22 & $\begin{array}{l}0.2 \\
24 \\
77\end{array}$ & $\begin{array}{l}8.3 \\
19 \\
1.6 \\
28\end{array}$ & 57 & $\begin{array}{l}29 \\
65 \\
5.5\end{array}$ & $\begin{array}{l}<\text { d.I. }{ }^{h} \\
1.4 \\
0.77 \\
2.2\end{array}$ & 68 & $\begin{array}{l}<\text { d.I. }^{h} \\
66 \\
35\end{array}$ \\
\hline $\begin{array}{l}\text { Filtrated fraction }<0.7 \\
\mu^{\mathrm{e}}\end{array}$ & $\begin{array}{l}\text { LMW } \\
\text { MMW } \\
\text { HMW } \\
\text { SPAHs }\end{array}$ & $\begin{array}{l}0.031 \\
53 \\
2.3 \\
55\end{array}$ & 78 & $\begin{array}{l}0.06 \\
96 \\
4.2\end{array}$ & $\begin{array}{l}3.9 \\
0.59 \\
19 \\
23\end{array}$ & 46 & $\begin{array}{l}17 \\
2.5 \\
81\end{array}$ & $\begin{array}{l}0.062 \\
0.45 \\
0.51 \\
1.0 \\
\end{array}$ & 32 & $\begin{array}{l}6.0 \\
44 \\
50\end{array}$ \\
\hline Colloidal fraction ${ }^{\dagger}$ & $\begin{array}{l}\text { LMW } \\
\text { MMW } \\
\text { HMW } \\
\text { ¿PAHs }\end{array}$ & $\begin{array}{l}- \\
34 \\
1.17 \\
35\end{array}$ & $50 \%$ & $\begin{array}{l}\text { <d.I. }^{\text {h }} \\
97 \\
3\end{array}$ & $\begin{array}{l}3.9 \\
<\text { d.I. }{ }^{\text {h }} \\
17 \\
<\text { d.I. }{ }^{h}\end{array}$ & $<$ d.I. $^{\mathrm{h}}$ & $\begin{array}{l}18 \\
<\text { d.I. } \\
81\end{array}$ & $\begin{array}{l}0.03 \\
<\text { d.I. }{ }^{h} \\
<\text { d.I. }{ }^{h} \\
0.3\end{array}$ & 1.0 & $\begin{array}{l}100 \\
<{ }^{\text {d.I. }}{ }^{h} \\
<\text { d.I. }\end{array}$ \\
\hline Dissolved fraction $^{g}$ & $\begin{array}{l}\text { LMW } \\
\text { MMW } \\
\text { HMW } \\
\text { ¿PAHs }\end{array}$ & $\begin{array}{l}0.031 \\
18 \\
1.2 \\
19\end{array}$ & 28 & $\begin{array}{l}0.15 \\
94 \\
5.8\end{array}$ & $\begin{array}{l}0.031 \\
43 \\
2.0 \\
45\end{array}$ & 88 & $\begin{array}{l}0.07 \\
96 \\
4.4\end{array}$ & $\begin{array}{l}0.03 \\
1.5 \\
1.9 \\
3.5\end{array}$ & 109 & $\begin{array}{l}0.9 \\
44 \\
55\end{array}$ \\
\hline
\end{tabular}

${ }^{\mathrm{a}} \mathrm{DIS} \%=$ distribution $\%$ calculated from the quantified $\sum \mathrm{PAHs}(\mu \mathrm{mol})$ in each Particulate, Filtrated, Colloidal and Dissolved fractions divided with the $\sum$ PAHs $(\mu \mathrm{mol})$ quantified in the Total fraction; ${ }^{b}$ REL $\%=$ relative $\%$ calculated by the $\mu$ mol of the LMW PAHs, $-\mathrm{M}$ and $-\mathrm{H}$ divided with the $\sum$ PAHs in each sample; ${ }^{\mathrm{c}}$ Total $=$ quantified $\sum \mathrm{PAHs}$ in the original sample; ${ }^{\mathrm{d}}$ Particulate $=$ calculated as PAHs quantified in Total - PAHs quantified in Filtrated; ${ }^{\mathrm{e}}$ Filtrated $=$ PAHs quantified in samples after filtrations through $0.7 \mu \mathrm{m}$ glass fibre filter; ${ }^{\mathrm{f}}$ Colloidal $=$ calculated as Filtrated PAHs - Dissolved; ${ }^{\mathrm{g}}$ Dissolved $=$ PAHs analysed on disk SPE. 
348 Moreover, the outlet sample of the Event 2 at Gårda contained $139 \mu \mathrm{g} / \mathrm{L}$ PAHs, almost three times 349 the inlet concentration. In contrast, the outlet of the Järnbrott had only about 5\% (3.2 $\mu \mathrm{g} / \mathrm{L})$ of the inlet concentration $(71 \mu \mathrm{g} / \mathrm{L})$, see the Discussion section for further details on these findings.

\section{Discussion}

352 The results obtained, for both the synthetic suspensions and the stormwater samples, showed that 353 the amount of PAHs found in the Particulate fractions vs. the Dissolved fractions follow their 354 hydrophobic properties. In most samples, > 50\% of the HMW PAHs were found in the Particulate 355 fractions, while the LMW and MMW PAHs were found to a higher extent in the Filtrated fractions. 356 In the synthetic suspensions, presence of colloids caused even the most hydrophobic HMW PAHs 357 to be found more equally represented in the Filtrated and the Particulate fractions, which supports 358 the finding by Kalmykova et al. (2013) that PAHs partition to the Particulate fraction is reduced in 359 the presence of colloids. This effect is in accordance with the molecular weight and hydrophobicity 360 of the compounds i.e. the partition to the Filtrated $=$ Colloidal + Dissolved fraction show a negative 361 correlation with $\log \mathrm{K}_{\text {ow }}$. Hypothesis (i) is strengthen by the results from the stormwater, as the 362 samples from Event 2 with heavy rain fall before sampling, contained more of the water soluble 363 LMW PAHs; the relative amount of the HMW PAHs were also highest in the samples with high 364 TSS, which also contained small particles.

365 For hypothesis ii) the amount of PAHs sorbed on inorganic particles (Fe) was about $50 \%$ of the 366 loads sorbed on the organic particles, the Fe + HA and HA suspensions, respectively (Table 1, 367 Particulate fraction). The difference was almost entirely due to the much lower LMW and MMW 368 PAHs sorption to Fe particles. This suggests that the most hydrophobic HMW PAHs partition to Fe 369 particles, while the LMW and MMW PAHs remain in the Dissolved fraction, which potentially 370 enhances their mobility. Among the Colloidal suspensions, the Fe + HA combination have resulted 371 in the highest particulate-bound PAHs, probably due to formation of the larger particles due to $\mathrm{Fe}$ 372 and HA agglomeration, as was shown in Kalmykova et.al. (2010) and Nielsen et al. submitted. The 373 Fe-n particles had a size of $44 \mathrm{~nm}$ in hydrodynamic, while the HA-n colloids were found to be 160 $374 \mathrm{~nm}$ in hydrodynamic diameter. The $\mathrm{Fe}+\mathrm{HA}$ combination have also resulted in the highest 375 Colloidal fraction, which is even more mobile than the Dissolved fraction.

376 For the third hypothesis iii) the amount of PAHs found in the Total fraction should be decreasing 377 from the inlet to the outlet in the settling facilities. For the Gårda facility this hypothesis can be rejected, but not for the Järnbrott pond. In fact, the highest concentration of PAHs at Gårda was 
found in the outlet of the Event 2, and it was threefold higher than the inlet concentration for the same event. Extreme situations like event 2 at Gårda (heavy rain, and sediment re-suspension) are unthinkable to use for evaluation of the treatment efficiencies, which require data for extended seasons, different types of events as described by intensity and duration, and sampling schemes adjusted according to the systems hydraulic retention time. Here, however, the results from Gårda highlight that during extreme situations more particulate matter than anticipated can be discharged, and with it, toxic trace metals, Table 2, and PAHs in the Particulate fraction, Table 3. At Järnbrott, a tenfold decrease of the outlet concentration of PAHs compared to the inlet concentration was observed (Table 4). The biggest decrease is seen for the Filtrated fraction, where the concentration has decreased 23-fold. Low concentrations of Colloidal-bound PAHs were found in the Järnbrott outlet that indicates that the pond, during the prevailing weather conditions, was working effective. However, repeated analysis is needed to confirm the ponds efficiency due to the large variability of the inlet composition, i.e. $77 \%$ of PAH were found in the Colloidal fraction in the inlet of the Event 1, which may lead to a different removal efficiency compared to the Event 2.

Relatively high amounts of HMW PAHs were found in the Järnbrott outlet.. Non-volatile organic carbon, representing the organic matter in the stormwater was analysed in all the samples and showed no statically significant difference between inlet and outlet samples. Therefore the higher amount of HMW PAHs in the outlet at Järnbrott can not be explained by the sorption to elevated concentration of dissolved organic matter. An increase in the NVOC concentration in the outlet compared to the inlet, due to enrichment in the pond, could otherwise have affected the result, as the presence of DOC is proven to decrease the partition of PAHs to larger particles (Kalmykova et al. 2013).

\section{Conclusions}

The stormwater in this study is polluted with PAHs originating from the highway runoff with concentrations in the higher range of the previously internationally reported levels. Substantial part of this pollution has been found in the Filtrated fraction, which may be difficult to retain by the conventional stormwater techniques, presented here by the sedimentation pond (Järnbrott) and a chain of sedimentation chambers (Gårda). In the Järnbrott pond, a tenfold decrease of the outlet concentration of PAHs compared to the inlet were found. Yet, a non-negligible PAHs concentration in the outlet sample, mainly found in the Dissolved fraction, may pose a risk to the environment. On 
410 the other hand, in the sedimentation chambers, the outlet concentration was higher than the inlet, 411 due to the re-suspension of the PAHs bound to sediment during the turbulent conditions of the 412 heavy rain. This highlights the risks of secondary pollution from the sedimentation-based systems. 413 The study of the PAHs distribution in the synthetic suspensions has confirmed considerable 414 distribution of the PAHs to Filtrated fractions and clarified the role of the studied particle 415 suspensions in the PAH distribution. It has been shown that the PAHs are distributed among the 416 fractions differently depending on the molecular weight; the LMW and MMW PAHs were mostly 417 found in the Filtrated fractions, while more of the HMW PAHs has been found in the Particulate 418 fractions. The Filtrated fraction was mostly constituted of the Dissolved pollutants, except for the 419 Fe+HA suspension, where Colloidal fraction was significant. The fact of such significant presence 420 of PAHs in Filtrated fraction potentially enhances their mobility. The amount of PAHs sorbed to the 421 mixture of the Fe-HA particles was the highest, while to the inorganic Fe particles - the lowest.

The results with high amounts of PAHs in the Filtrated fractions, observed for both the synthetic 424 solutions and the stormwater, show the importance of development of advanced techniques for stormwater treatment that are able to remove the PAHs in the colloidal and dissolved phases. In particular, the stormwater treatment technologies needs to be complemented with techniques that are able to reduce the dissolved PAHs, e.g. sorption filters, and colloidal-bound PAHs by for example oxidation, ozonolysis or UV-degradation.

\section{Acknowledgments}

431 The Technical University of Denmark is acknowledged for Katrine Nielsens Nordic Five Tech 432 (N5T) PhD scholarship, and the technical staff at DTU, Denmark and Chalmers, Sweden is 433 acknowledged for their assistance in the lab and field, in particular Mikael E. Olsson for the PAHs 434 analysis guide, Mona Pålsson for assistance in the lab and Lars-Ove Sörman for assistance during 435 collection of the stormwater.

\section{References}

437 Aryal R., Furumai H., Nakajima F. and Beecham S., 2013, Variation in PAH patterns in road 438 runoff, Water Science \& Technology, 67.12, 2699-2705 
Badin, A.-L., Faure, P., Bedell, J.-P., \& Delolme, C. 2008, Distribution of organic pollutants and natural organic matter in urban storm water sediments as a function of grain size. Science of the

441 Total Environment, 403(1-3), 178-187.

442 Barbosa A.E., Fernandes J.N. and L.M. David, 2012, Key issues for sustainable urban stormwater 443 management, water research, 46, 6787-6798

444 Birch H., Gouliarmou V., Lützhøft H.-C. H., Mikkelsen P. S. and Mayer P, 2010, Passive Dosing to 445 Determine the Speciation of Hydrophobic Organic Chemicals in Aqueous Samples, Analytical 446 Chemistry, 82, 1142-1146

Bin G., Cao X., Dong Y,. Luo Y. and Ma L. Q., 2011, Colloid Deposition and Release in Soils Colloid Deposition and Release in Soils, Environmental Science and Technology, 41, 336-372

449 Birch, H., Mikkelsen, P. S., Jensen, J. K., \& Lützhøft, H.-C. H., 2011. Micropollutants in stormwater runoff and combined sewer overflow in the Copenhagen area, Denmark. Water Science 451 and Technology, 64(2), 485-493.

Björklund K., Strömvall A-M. and Malmqvist P-A., 2011, Screening of organic contaminants in urban snow, Water Science \& Technology, 64.1, 206-213

\section{Boyd S. A., Sheng G., Teppen B. J., and Johnston C. T., 2001, Mechanisms for the adsorption of} substituted nitrobenzenes by smectite clays, Environmental Science technology, 35, 4227-4234

Brown J. N. and Peake B. M., 2003, Determination of colloidally-associated polycyclic aromatic hydrocarbons in fresh water using C18 solid phase extraction disks, Analytica Chimica Acta, 486, 159-169

459 Celis R., De Jonge H., De Jonge L. W., Real M., Hermosín M. C., and Cornejo J., 2006, The role of 460 mineral and organic components in phenanthrene and dibenzofuran sorption by soil, European 461 Journal of Soil Science, 57, 308-319

462 Cho, D. Lee, S. Frey, M.W., 2012, Characterizing zeta potential of functional nanofibers in a 463 microfluidic device, Journal of Colloid Interface Science, 372, 252-260.

466 Deffontis S., Breton A., Vialle C., Montréjaud-Vignoles M., Vignoles C. and Sablayrolles C., 2013, 467 Impact of dry weather discharges on annual pollution from a separate storm sewer in Toulouse, 468 France, Science of the Total Environment, 452-453, 394-403

469 Eriksson E., Baun A., Mikkelsen P. S. and Ledin A., 2007, Risk assessment of xenobiotics in 470 stormwater discharged to Harrestrup $\AA$, Denmark, Desalination, 215, 187-197

Florence T. M., 1982, Development of physic and chemical speciation procedures to investigate the toxicity of copper, lead, cadmium and zinc towards aquatic biota. Analytica Chimica Acta, 141, 7394 
Grolimund D. and Brokovec M, 2005, Colloid-facilitated transport of strongly sorbing contaminants in natural porous media: Mathematical modeling and laboratory column experiments, Environmental Science Technology, 39, 6378-6386

Göbel, P., Dierkes, C. and Coldewey, W.G., 2007. Storm water runoff concentration matrix for urban areas, Journal of Contaminant Hydrology, 91, 26-42.

Howitt J. A., Mondon J., Mitchell B. D., Kidd T. and Eshelman B. 2014 Urban stormwater inputs to an adapted coastal wetland: Role in water treatment and impacts on wetland biota, Science of the Total Environment, 485-486, 534-544.

Hwang H. and Foster G., 2006, Characterization of polycyclic aromatic hydrocarbons in urban stormwater runoff flowing into the tidal Anacostia River, Washington, DC, USA, Environmental Pollution, 140, 416-426

Kalmykova Y., Rauch S., Strömvall A-M., Morrison G., Stolpe B. and Hassellöv M., 2010, Colloid-facilitated metal transport in peat filters. Water Environment Research, 82, 506-511

Kalmykova Y., Björklund K. , Strömvall A-M. and Blom L., 2013, Partitioning of polycyclic aromatic hydrocarbons, alkylphenols, bisphenol $A$ and phthalates in landfill leachates and stormwater, Water Research, 47, 1317-1328

Kalmykova Y., Moona N., Strömvall A-M. and Björklund K., 2014, Sorption and degradation of petroleum hydrocarbons, polycyclic aromatic hydrocarbons, alkylphenols, bisphenol A and phthalates in landfill leachate using sand, activated carbon and peat filters, Water Research, 56, 246-257

Kayhanian M., McKenzie E. R., Leatherbarrow J. E., Young T. M., 2012, Characteristics of road sediment fractionated particles captured from paved surfaces, surface run-off and detention basins, Science of the Total Environment, 439, 172-186

Lead R. J. and Wilkinson K. J., 2006, Aquatic colloids and nanoparticles: current knowledge and future trends, Environmental Chemistry, 3, 159-171

Liu J.J., Wang C. X. and Fan B., 2011, Characteristics of PAHs adsorption on inorganic particles and activated sludge, Bioresource Technology, 102,5305-5311

Liu, J., Sample, D.J., Bell, C., Guan, Y. 2014, Review and research needs of bioretention used for the treatment of urban stormwater, Water, 6, 1069-1099.

Luo L., Zhang D., and Ma Y., 2008, Evaluation of impacts of soil fractions on phenanthrene sorption, Chemosphere, 72, 891-896

Makepeace D. K., Smith D. W. and Stanly S. J., 1995, Urban stormwater quality: Summary of contaminant data. Environmental Science and Technology, 25, 93-139

Mitra S., 2003, Sample preparation techniques in analytical chemistry, Wiley-Interscience, volume $162,104-108$

Moilleron R., Gonzalez A., Chebbo G. and Thévenot D. R., 2002, Determination of aliphatic hydrocarbons in urban runoff samples from the "Le Marais"' experimental catchment in Paris centre, Water Research, 36, 1275-1285 
Murakami M., Nakajima F. and Furumai H., 2005, Size- and density-distributions and sources of

515 polycyclic aromatic hydrocarbons in urban road dust, Chemosphere, 61, 783-791

516 Nielsen K., Mørch-Madsen A., Baun A. and Eriksson E, submitted, Characterisation and stability studies of humic acid nano-sized colloids and iron nano-sized particles intended for simulated stormwater experiments, Submitted to Environmental Pollution

Nielsen K., Mørch-Madsen A., Mikkelsen P. S. and Eriksson E., 2015, Effect of Disc Filtration with and without Addition of Flocculent on Nano- and Micro-Particles and Their Associated Polycyclic Aromatic Hydrocarbons in Stormwater, Water, 7, 1306-1323

Norin M. and Strömvall A-M., 2004, Leaching of organic contaminants from storage of reclaimed asphalt pavement, Environmental Technology, 25, 323-340

Palm L. M. N., Carboo D., Yeboah P. O., Quasie W J., Gorleku M. A. and Darko A., 2011, Characterization of Polycyclic Aromatic Hydrocarbons (PAHs) Present in Smoked Fish from Ghana, Advance Journal of Food Science and Technology, 3, 332-338 P., 2013, Water suspended nanosized particles released from nonairborne brake wear debris, Wear, 306, 89-96

Pettersson T. J. R., 1998, Water quality improvement in a small stormwater detention pond, Water science technology, 38, 115-122

Pettersson T. J. R., Strömvall A-M. and Ahlman S., 2005, Underground sedimentation systems for treatments of highway runoff in dense city areas, $10^{\text {th }}$ International conference on urban drainage, Copenhagen/Denmark, 21-26 August

Pitcher S. K., Slade R.C.T. and Ward N.I., 2004, Heavy metal removal from motorway stormwater using zeolites, Science of the Total Environment, 334-335, 161 - 166

537 Qian Y., Posch T. and Schmidt T., 2011, Sorption of polycyclic aromatic hydrocarbons (PAHs) on 538 glass surfaces, Chemosphere, 82, 859-865

539 Reichardt C., 2003, Solvents and solvent effects in organic chemistry, Wiley-VCH, third edition, 540 Smith et al., 2009

541 Sato, E., Matsumoto, K., Okochi, H. and Igawa, M. 2006. Scavenging Effect of Precipitation on 542 Volatile Organic Compounds in Ambient Atmosphere. Bulletin of the Chemical Society of Japan, 79 543 (8), 1231-1233.

544 Strömvall A-M., Norin M. and Pettersson T. J. R., 2007, Organic contaminants in urban sediments and vertical leaching in road ditches, $8^{\text {th }}$ Highway and urban environment Symposium,

547 U.S. EPA, 1995, Toxicological profile for Polycyclic Aromatic Hydrocarbons, U.S. EPA National 548 Exposure Research Laboratory (NERL) United States of America. 
549 U.S. EPA Method 160.2, 1971, Residue, non-filterable (gravimetric, dried at 103-105), U.S. EPA

550 National Exposure Research Laboratory (NERL) United States of America 551 (http://www.caslab.com/EPA-Methods/PDF/EPA-Method-160-2.pdf) (accessed 20.03.2015)

552 U.S. EPA Method 3510C, 1996, Separatory funnel liquid-liquid extraction, U.S. EPA National 553 Exposure Research Laboratory (NERL) United States of America

554 (http://www.epa.gov/epawaste/hazard/testmethods/sw846/pdfs/3510c.pdf) (accessed 20.03.2015)

555 Van Metre P., Mahler B. J. and Furlong E. T., 2000, Urban Sprawl Leaves Its PAH Signature, 556 Environmental Science Technology, 34, 4064-4070

557 Waksmundzka-Hajnos M. and Wronska B., 1996, Retention Behaviour of Model Solutes on Mixed 558 Silica - magnesua adsorbents by TLC. Comparison with the adsorption properties of Florisil, 559 Chromatographia, 43, No. 7/8, 405-412

560 Wang C., Wang F, Wang T, Bian Y, Yang X, Jiang X, 2010, PAHs biodegradation potential of 561 indigenous consortia from agricultural soil and contaminated soil in two-liquid-phase bioreactor 562 (TLPB), Journal of Hazardous Material, 176, 41-47

Wik A. and Dave G. 2009, Occurrence and effects of tire wear particles in the environment - A critical 565

566 Xanthopoulos C. and Hahn H.H., 1990, Pollutants attached to particles from drainage areas, The 567 Science of the Total Environment, 93, 441-448

568 Zheng Y., Luo X, Zhang W, Wu B, Han F, Lin Fa and Wang X, 2012, Enrichment behavior and 569 transport mechanism of soil-bound PAHs during rainfall-runoff events, Environmental Pollution, $570 \quad 171,85-92$ 